Motrivivência Ano XXIII, No 36, P. 111-128 Jun./2011

doi: 10.5007/2175-8042.2011v23n36p111

\title{
A CULTURA CORPORAL COMO OBJETO DE ESTUDO NOS REFERENCIAIS CURRICULARES DO ENSINO FUNDAMENTAL DA PARAÍBA
}

\author{
Jeimison Araújo Macieira' \\ Áurea Augusta R Mata ${ }^{2}$ \\ Jorge F Hermida $^{3}$
}

\section{RESUMO}

O artigo procura fazer um panorama das discussões que estão acontecendo em nível nacional no processo de reformulação dos Referenciais Curriculares Básicos de Educação Física, situando-o nos estados do Paraná, Pernambuco, Bahia e, em particular, na Paraíba. Observa-se nas discussões desenvolvidas nos estados citados uma tendência por construir seus referenciais curriculares tendo como objeto de estudo a Cultura Corporal. Esta proposta tem como perspectiva o desenvolvimento omnilateral e afirma o materialismo histórico-dialético como teoria do conhecimento. Reconhece a escola como instrumento de luta, por conferir elementos para uma melhor compreensão da realidade.

Palavras-chave: Cultura Corporal; Educação Física escolar; Referenciais Curriculares Básicos de Educação Física.

1 Mestre pelo Programa de Pós-graduação em Serviço Social da UFPB. Estudante de Filosofia da UFPB. Contato: jeimison89@hotmail.com

2 Mestranda do Programa de Pós-Graduação em Educação na Universidade Federal da Paraíba;Professora de Educação Física da rede municipal de ensino de João Pessoa. Membro do Laboratório de Estudos e Pesquisas em Educação Física \& Esporte e Lazer da Paraíba (LEPELPB/ UFPB). Contato: aureaaugusta@hotmail.com

3 Professor do Programa de Pós-Graduação em Educação na Universidade Federal da Paraíba;Doutor em Filosofia e História da Educação (UNICAMP). Líder do Laboratório de Estudos e Pesquisas em Educação Física \& Esporte e Lazer da Paraíba (LEPELPB/UFPB).

Contato: jorgefernandohermida@hotmail.com 


\section{Introdução}

Este estudo tem como objetivo fazer um panorama das discussões que estão acontecendo em nível nacional no processo de reformulação dos Referenciais Curriculares Básicos de Educação Física, situando-o nos estados do Paraná, Pernambuco, Bahia e, em particular, no contexto paraibano. ${ }^{4}$

$O$ interesse pela questão dos processos de reformulação dos referenciais curriculares é um dos temas mais atuais e polêmicos na pauta obrigatória de congressos e seminários que têm como tema central a Educação Física escolar.

$\mathrm{O}$ artigo toma como ponto de partida os textos e o contexto histórico de fins da década de 1990, época em que o Brasil retoma suas liberdades e legitimidade social e política e a sociedade como um todo (a sociedade civil e a sociedade política) começa a debater novos projetos para a educação nacional. É dessa época que datam os primeiros projetos de leis que procuram regulamentar legal e pedagogicamente à Educação Física nos tempos e espaços escolares, que serviram como fundamento sólido para chegar à elaboração dos Referenciais
Curriculares para a Educação Física da Paraíba, em 2010.

Embora os referenciais sejam propostas oficiais que vêm sendo construídas estadualmente, eles têm uma característica particular: dependendo do modo em que são construídos e do nível de participação e envolvimento dos professores da rede estadual de ensino, eles abrem a possibilidade para a construção coletiva de alternativas emancipatórias. Uma perspectiva que pretenda essa natureza precisa tomar como referência o acontecido na história recente da Educação Física brasileira a década de 1980 até nossos dias, pois é nela que começam a manifestar-se "[...] os primeiros elementos de uma crítica a sua função sócio-política conservadora no interior da escola" (Coletivo de Autores, 1992, p. 49). Porém, esse avanço no campo das ideias não foi acompanhado na realidade concreta, "no chão da escola", já que se percebe um grande descompasso no que diz respeito à qualidade da produção teórica dos intelectuais brasileiros desenvolvida principalmente nas universidades federais e o que vêm acontecendo na realidade escolar concreta.

Com a discussão e construção de referenciais nos diversos

4 Assuntos vinculados a este artigo foram apresentados no V Encontro Brasileiro de Educação e Marxismo (EBEM), realizado na cidade de Florianópolis, de 11 a 14 de abril de 2011. 
estados do nosso país, têm-se a oportunidade histórica de propiciar uma melhor socialização de conhecimentos e saberes vinculados com nosso campo de conhecimento, construídos desde perspectivas educacionais críticas. No entendimento dos autores deste artigo, a opção pedagógica, teórica e metodológica capaz de dar conta do processo de socialização de conhecimentos produzidos historicamente pela humanidade é a da cultura corporal, ancorada no materialismo histórico e dialético.

Além desta introdução, o artigo esta organizado em quatro tópicos mais as considerações finais. "Antecedentes legais e pedagógicos" que trata de forma breve do percurso histórico que tiveram os processos de regulamentação legal e pedagógica da Educação Física escolar, até a aprovação das Diretrizes Curriculares Nacionais para a Educação Básica, em 2001. $\mathrm{O}$ item seguinte apresenta uma análise dos processos de elaboração dos Referenciais Curriculares de alguns estados, a saber, Paraná, Bahia e Pernambuco, trazendo a baila como se procedeu nesses estados a construções desses documentos. Vale salientar que nossa intenção não é aprofundar as discussões sobre o processo em cada estado, mas, sobretudo, estabelecer um panorama das discussões que estão acontecendo nacionalmente, principalmente naqueles estados em que o referencial esta apontando para a construção fundamentada em teorias críticas de educação contrahegemônicas. Em "A construção dos Referenciais Curriculares do Estado da Paraíba" relata como aconteceu o processo de construção dos Referenciais Curriculares do Estado da Paraíba, desde a publicação do edital $n^{\circ}$. 01/2010/SEAD/SEEC (processo seletivo simplificado para contratação de pessoal em caráter excepcional para a elaboração dos referenciais), até sistematização a versão final do documento. No ítem 4, "Fundamentos teóricos e metodológicos do Referencial do Estado da Paraíba" são apresentadas as principais contribuições dos referenciais teóricos escolhidos para a construção da versão final do documento. $\mathrm{O}$ artigo se encerra com a apresentação das considerações finais.

\section{Antecedentes legais e peda- gógicos}

Os primeiros esforços por regulamentar legal e pedagogicamente a Educação Física escolar brasileira datam da década dos anos 1990. Nessa época, após aprovar uma nova Constituição Federal em 1988, que dotou de legalidade e legitimidade política à sociedade 
brasileira - deixando desta maneira para trás mais de vinte anos de ditadura militar - é aprovada uma nova Lei de Diretrizes e Bases da Educação Nacional (LDBEN, em 1996), os Parâmetros Curriculares Nacionais (PCN's, em 1998), o Referencial Curricular Nacional para a Educação Infantil (RCNEI), de 1998, a lei 9.696, de 1998, a lei 10.328, de dezembro de 2001, as Diretrizes Curriculares Nacionais para a Educação Física brasileira (DCN's, em 2001), e a lei 10.793, de 1 de dezembro de 2003.

Os processos de elaboração, discussão e aprovação da Lei Maior da educação nacional (LDBEN) foram considerados na época uma prioridade nacional, porém, eles não estiveram isentos de dificuldades. Após ter sido eleito presidente da República, a educação foi uma das cinco prioridades do governo de Fernando Henrique Cardoso (FHC), junto com a agricultura, segurança, emprego e saúde. Após assumir a Presidência, a elaboração de leis educacionais começa a passar por dificuldades, produto da interferência do Executivo no Congresso Nacional. As dificuldades dizem respeito ao caminho que teve que tramitar a LDBEN até sua aprovação final, pois, ao assumir FHC, o Poder Executivo adota uma nova forma de fazer política, menos participativa e mais centralizada. Por exemplo, o projeto de lei originário, elaborado por movimentos sociais defensores do ensino público e gratuito e apresentado na Câmara Federal pelo deputado Octávio Elísio em dezembro de 1988 foi alterado. Até chegar a sua versão final, teve três projetos substitutivos, de natureza ideológica e antitética diferente. $\mathrm{E}$ a lei teve que tramitar mais de oito anos no Congresso Nacional, até ser aprovada em 20 de dezembro de 1996.

Como era de pressupor, o projeto aprovado foi o oriundo do Poder Executivo e do Ministério da Educação de FHC.

A "nova forma de fazer política" é fácil de ser fundamentada. Com a posse de $\mathrm{FHC}$, o processo de reformas atingiu várias áreas da realidade brasileira. Dentre as mais relevantes, junto à reforma educativa, houve a reforma do Estado. Mudanças macroeconômicas levaram a reorganização da economia e trouxeram para o país a recuperação do investimento privado, a privatização das empresas estatais e a estabilidade monetária. Para o setor público, o governo elaborou o Programa Diretor para a Reforma do Aparelho do Estado (PDRAE). Para Hermida (2009), com a reeleição de FHC na Presidência da República a "cruzada neoliberal" se consolida no poder, 
...continuando a subscrever a estratégia que os países capitalistas centrais determinaram para os países capitalistas periféricos, ou em vias de desenvolvimento: o controle da inflação, a privatização das empresas estatais e estabilidade monetária como objetivo prioritário do governo, Com isto, o monetarismo e o liberalismo se tornaram a religião oficial das políticas econômicas brasileiras, Sob a égide da estratégia do consentimento, as classes dominantes continuaram a impor seus projetos hegemônicos. Dentre eles, o educativo (2009, p. 21).

Com este tipo de política alinhada à necessidade de implantar para o país o modelo de "Estado Mínimo", as instituições educacionais começam a sofrer um processo de sucateamento e o arrocho salarial dos trabalhadores da educação foi "institucionalizado".

Com as eleições nacionais de 2002, que elegem como presidente da República Luíz Inácio Lula da Silva, se implanta na política um assunto extremamente polêmico, um problema estritamente político e ideológico, a saber, o Partido dos Trabalhadores (PT) que esteve, em termos políticos, opondo-se sistematicamente à proposta educacional construída pelo governo de $\mathrm{FHC}$, ao assumir a presidência o governo de Lula continua mantendo vigente as políticas econômica e educacional elaboradas pelo seu antecessor.

No que diz respeito à Educação Física, do ponto de vista legal citada no art. 26 da nova LDBEN parágrafo $3^{\circ}$. "Educação Física, integrada à proposta pedagógica da escola, é componente curricular da Educação Básica, ajustando-se às faixas etárias e às condições da população escolar, sendo facultativa nos cursos noturnos". Com a aprovação lei 10.328, em 12 de dezembro de 2001, ela acrescenta a palavra "obrigatório" após a expressão curricular, constante no parágrafo supracitado. Com a sanção no Senado Nacional da lei 10.793, de 2003, o parágrafo $3^{\circ}$. sofreu nova alteração pois passa a vigorar acrescentando a facultatividade para os alunos que cumpram jornadas de trabalho igual ou superior a seis horas, os que cumpram 30 anos de idade, que estiverem prestando serviço militar e para aqueles que tenham prole.

Semelhantemente ao acontecido com os processos de aprovação das leis educacionais, do ponto de vista pedagógico, os documentos elaborados para orientarem legalmente os processos pedagógicos da Educação Física escolares sofreram 
o mesmo processo de interferência da parte do Poder Executivo nos governos de FHC. Os principais documentos elaborados que contêm referências que tratam de conteúdos vinculados à Educação Física são: os Parâmetros Curriculares Nacionais (PCN's, de 1998), o Referencial Curricular Nacional Para a Educação Infantil (RCNEI, de 1998), e a lei 10.328, de dezembro de 2001, que apresenta as Diretrizes Curriculares Nacionais para a Educação Básica (DCN's).

A nova conjuntura legal conquistada pela Educação Física escolar a partir da nova LDBEN - pois ela passa ser componente curricular obrigatório das escolas brasileiras, Ihe permitiu ganhar um status qualitativo diferente. Ao ser componente curricular ela ganha status de disciplina e assim o trato com o conhecimento que a caracteriza passa a ser diferente. $\mathrm{Na}$ opinião de Castellani Filho (1997) e Hermida (2009), quando ela passa a ser componente curricular, ela abre a possibilidade de que as diferentes concepções de Educação Física escolar hoje existentes possam ser viabilizadas e desenvolvidas objetivamente, embora paire, na opinião dos autores, o "fantasma dos PCN's".

Os PCN's é um documento que foi criado para ordenar a Educação Física brasileira no aspecto especificamente pedagógico. Para a Secretaria de Educação Fundamental do Ministério de Educação, os PCN's:

...constituem um referencial de qualidade para a educação no Ensino Fundamental em todo o país. Sua função é orientar e garantir a coerência dos instrumentos no sistema educacional (...) subsidiando a participação de técnicos e professores brasileiros, principalmente daqueles que se encontram mais isolados, com menor contato com a produção pedagógica atual (BRASIL-INEP, 1997, p. 13).

O RCNEI é um dos principais documentos elaborados pelo governo nacional para garantir o direito à educação das crianças de zero a seis aos de idade. Ele foi elaborado no ano de 1988 atendendo a determinações da LDBEN. Seus três volumes, que procuram referenciar atividades educacionais desenvolvidas em creches, entidades equivalentes e pré-escolas. Organizado em linguagens (Música, Artes Visuais, Linguagem oral e escrita, Natureza e sociedade, Matemáticas e Movimento), procura subsidiar a elaboração de projetos educativos, o planejamento e o funcionamento de creches e escolas de todo o país. 
As Diretrizes Curriculares Nacionais para a Educação Básica se constituem de definições doutrinarias sobre princípios, fundamentos e procedimentos a serem observados na organização pedagógica e curricular de cada unidade escolar integrante dos diversos sistemas de ensino, tendo em vista a vinculação da educação com o mundo do trabalho e a prática social, consolidando a preparação para o exercício da cidadania. Para a Câmara de Educação Básica do Conselho Nacional de Educação,

Não cabe mais a este Colegiado fixar mínimos curriculares nacionais por curso ou modalidade de ensino. Cabe, sim, fixar Diretrizes Curriculares Nacionais que orientem os sistemas de ensino na tarefa de apoiar o desenvolvimento dos projetos pedagógicos concebidos, executados e avaliados pelas escolas, com a efetiva participação de toda a comunidade escolar, em especial dos docentes.

Flexibilidade para atuação dos sistemas de ensino e das escolas, de todos os níveis e modalidades, bem como apoio, orientação e avaliação da qualidade do ensino por parte do Poder Público são dois dos pilares da Educação Nacional pós-LDB 96, ao lado do zelo pela apren- dizagem dos alunos e do compromisso com resultados, em termos de desenvolvimento da capacidade de aprendizagem e de constituição de competências que conduzam o aluno à progressiva autonomia intelectual e o coloque em condições de continuar aprendendo (DCN's, 2001, p. 05).

Os três documentos oficiais que orientam do ponto de vista pedagógico a Educação Física escolar têm uma característica em comum: seus projetos iniciais e produtos finais são oriundos dos Poderes Executivos dos governos de FHC ( $\mathrm{PCN}$ 's e RCNEI) e de Luiz Inácio Lula da Silva (DCN's). Os dois primeiros foram elaborados por assessores governamentais (inclusive alguns estrangeiros) contratados pelo MEC e o último, pelo colegiado da Câmara de Educação Básica do Conselho Nacional de Educação. Os três documentos não permitiram a participação de sindicatos, associações e movimentos populares defensores do ensino público, gratuito e obrigatório. $E$, finalmente, $O$ principal: os documentos ignoram as valiosas contribuições que diversas formas de conceber a Educação Física que, com o passar do tempo, concretizaram originais e inovadoras propostas 
pedagógicas desde fins da década de $1980^{5}$.
Iniciamos as análises dos processos de elaboração dos Referenciais Curriculares de alguns estados, a saber, Paraná, Bahia, Pernambuco e Paraíba, trazendo a baila como se procedeu nesses estados a construções desses documentos. Vale salientar que nossa intenção não é aprofundar as discussões sobre o processo em cada estado, mas, sobretudo, estabelecer um panorama das discussões que estão acontecendo nacionalmente, principalmente naqueles estados em que o referencial esta apontando para a construção de referenciais fundamentados em teorias críticas de educação antihegemônicas, que procure contribuir para a desconstrução do modelo capitalista de educação dominante no Brasil e na maioria dos países do mundo ocidental, em favor de uma proposta alternativa e emancipadora. Ademais,
Faz-se imprescindível à realização de análises mais rigorosas e radicais da realidade social atual, especialmente no interior da escola e, a elaboração de uma teoria pedagógica mais avançada que reconheça a cultura corporal como objeto de estudo da disciplina Educação Física, sem perder de vista os objetivos relacionados com a formação corporal, física, dos alunos, mas situando-os no âmbito da vida real de uma sociedade de classes (ESCOBAR, 2006).

Desta feita, em linhas gerais, o projeto de construção das Diretrizes Curriculares da Educação Básica do Estado do Paraná (DCEBPR) foi resultado de um processo de discussões coletivas ocorridas entre os anos de 2004 e 2008, que envolveu professores de diversas áreas da rede estadual de ensino.

Durante os anos de 2004 e 2006, a Secretaria de Estado da Educação promoveu encontros, simpósios e semanas de estudos pedagógicos para elaboração dos textos das DCEB-PR. Em 2007 e 2008, a equipe pedagógica do Departamento de Educação Básica

5 A questão vinculada à elaboração das propostas pedagógicas oficiais elaboradas pelos governos para a educação em geral e a Educação Física escolar em particular é um tema de grande importância para os autores deste trabalho. No entanto, por motivos de espaço, optamos por priorizar os processos de reformulação dos Referenciais Curriculares da Educação Básica, em especial aqueles vinculados com a reformulação dos referenciais para a Educação Física escolar. 
(DEB) percorreu os 32 núcleos regionais de educação, realizando um evento chamado "DEB itinerante", o qual ofereceu aos professores alocados nas regionais 16 horas de formação continuada (PARANÁ, 2008). Antes disso, todo o processo de elaboração das diretrizes se deu balizado em algumas constatações, são elas: o final do período da ditadura militar no Brasil e, posterior emergência das teorias criticas da educação, as quais tinham o interesse de redemocratizar a sociedade e, com isso, a educação; e a identificação da incorporação nas políticas públicas da pedagogia históricocrítica (SAVIANI, 2008).

Para as Diretrizes Curriculares da Educação Básica - Educação Física (DCEB-EF), o documento manteve a estrutura formal definida para as demais disciplinas e seguindo uma concepção crítica, ou seja,

Para as teorias críticas, nas quais estas diretrizes se fundamentam, o conceito de contextualização propicia a formação de sujeitos históricos - alunos e professores - que, ao se apropriarem do conhecimento, compreendem que as estruturas sociais são históricas, contraditórias e abertas (PARANÁ, 2008, p. 30)

Não obstante, ainda em torno do documento, este manteve a seguinte organização: inicia-se delineando acerca da dimensão histórica da disciplina; os fundamentos teórico-metodológicos; os conteúdos estruturantes; os encaminhamentos metodológicos; a avaliação e as referencias. As Diretrizes Curriculares para disciplina Educação Física do Estado do Paraná apontam para a construção de um currículo voltado para a formação de sujeitos críticos e reflexivos e, sobretudo, que consigam transformar a realidade a qual estão submetidos. A proposta de ensino de Educação Física que fundamenta todo o documento é a Crítico-superadora e a proposta pedagógica que a sustenta é a Pedagogia Histórico-crítica.

No estado da Bahia, a construção dos Referenciais Curriculares iniciou com o trabalho de definição das Diretrizes Curriculares do Ensino Fundamental em 1994 e, as Orientações Curriculares para o Ensino Médio em 2005. Para os anos de 2010 e 2011, a Secretaria de Educação do Estado da Bahia em conjunto com o Grupo LEPEL/ FACED/UFBA, organizou uma série de atividades para a elaboração coletiva dos referenciais, divididas em quatro momentos, são eles:

1. Debate acerca do projeto histórico, formação humana, teoria educacional e pedagógica, cultura corporal;

2. Evento científico para debater formação de professores, a escola e o trabalho pedagógico; 
3. Aprofundamento dos estudos, realizado no Programa de Pós-Graduação em Educação da FACED/UFBA, com a participação dos professores da rede e diálogo com os professores que constroem as propostas de Pernambuco, Paraná, Rio Grande do Sul; e finalmente,

4. Apresentação de proposições superadoras, levando em consideração o diagnóstico da realidade da Educação Física na rede estadual da Bahia.

Esse processo de construção optou pela perspectiva CríticoSuperadora, pois esta admite para a reflexão pedagógica algumas características específicas no trato com o conhecimento, a saber, diagnóstica, judicativa e teleológica. Ela busca elementos da realidade social, julgando-os a partir de uma ética, que defende os interesses de uma determinada classe social apontando um caminho, buscando uma direção (COLETIVO DE AUTORES, 1992), em defesa, nesse caso, da classe trabalhadora. Atualmente o processo de construção das diretrizes se encontra no quarto e último momento.

Já em Pernambuco, o processo de construção dos referenciais curriculares, recebe o nome de Orientações Teórico-metodológicas. Ele se deu a partir de um processo histórico, o qual considerou o acúmulo das produções deste componente curricular no cenário das políticas educacionais. A partir do convite feito pela Secretaria de Educação (SEDE) do Estado de Pernambuco foi institucionalizada uma parceria entre a Universidade de Pernambuco (UPE) e a Secretaria de Educação do Estado. Essa parceria colocou em prática a proposta de uma formação continuada, voltada aos professores da rede estadual.

A sistematização do documento foi resultado de estudos, discussões e produções realizadas pela comissão e pela SEDE, e o processo de elaboração aconteceu na forma de seminários, foram eles: seminários iniciais de diagnose, seminários de elaboração preliminares, seminários regionais 2009 e seminário de socialização da produção. (PERNAMBUCO, 2008).

Percebe-se no documento a adoção de uma perspectiva critica de educação e Educação Física, a qual admite como princípios norteadores a formação humana, o currículo na escola, a dinâmica curricular e a realidade dos alunos. A semelhança do acontecido nos estados do Paraná e Pernambuco, a disciplina Educação Física optou pela abordagem Crítico-superadora, "por perceber que essa permanece na essência de todos os documentos governamentais utilizados" (PERNAMBUCO, 2008).

Assim como, é visível, que nesses três estados os processos de 
discussão e construção de Diretrizes Curriculares adotou perspectivas críticas de educação e Educação Física, que denotam a necessidade de garantir aos alunos pertencentes as respectivas redes estaduais de ensino a possibilidade de compreender os conteúdos afeitos a esta disciplina, tendo como objeto de estudo a cultura corporal No nosso entendimento, observa-se um avanço teórico e uma provável perspectiva de elevação do padrão cultural dos alunos, tendo em vista que estarão submetidos a uma perspectiva de ensino que tem como finalidade a socialização do conhecimento produzido historicamente pela humanidade na sua vida em sociedade. São justamente esses conhecimentos na perspectiva da cultura corporal que permitem o desenvolvimento do pensamento crítico, historicamente sonegado aos filhos da classe trabalhadora. A apropriação do saber "burguês" para dotá-lo de novos significados permitirá à classe trabalhadora é essencial para desarticular os interesses burgueses e colocando-os a serviço de sua classe. E assim poder identificar as contradições do atual modelo de educação e produção que é o responsável das desigualdades sociais que caracterizam as sociedades divididas em classes.

\section{A construção dos Referenciais Curriculares do Estado da Paraíba}

O processo de construção dos Referenciais Curriculares do Estado da Paraíba teve início através do edital $n^{\circ}$. 01/2010/SEAD/SEEC, tornou público o processo seletivo simplificado para contratação de pessoal em caráter excepcional para a elaboração dos referenciais. Foi motivado pela necessidade percebida pela, até então, gestão estadual, de alterar o texto, admitindo mudanças teóricas que culminassem em transformações didáticas, pedagógicas e metodológicas nos referenciais curriculares e na prática pedagógica dos professores, uma vez que o último currículo do Ensino Fundamental vigente no Estado datava de 1988. Para o trabalho foram contratados 19 profissionais $^{6}$, para as seguintes áreas: Linguagens, Códigos e suas Tecnologias; Ciências da Natureza; Matemática e suas Tecnologias; Ciências Humanas e suas Tecnologias e Diversidade Sociocultural.

Após a conclusão do processo seletivo, iniciaram-se, os

6 Sendo um coordenador geral, um revisor técnico e 16 consultores. 
trabalhos de elaboração, com a primeira reunião geral junto à coordenação do projeto, os consultores das áreas e o revisor técnico em julho de 2010. Na reunião, decidiu-se o formato para a construção coletiva dos RCEF, assim estabelecido: duas oficinas pedagógicas com a presença dos professores da rede estadual de ensino; reuniões quinzenais com a coordenação do projeto; reuniões periódicas entre consultores das áreas correlatas para tratar das possíveis articulações entre as disciplinas; reuniões periódicas com o outro consultor (no caso da disciplina ter dois consultores) para elaboração do texto. Também foi definida a estrutura do texto: inserção da disciplina no Ensino fundamental; objetivos; competências formativas no ensino da disciplina; conceitos necessários ao ensino da disciplina; conteúdos estruturantes e temas transversais, procedimentos didático-metodológicos; avaliação; e finalmente os referenciais teóricos.

Posteriormente os consultores $^{7}$ fizeram um levantamento de documentos, textos, livros, diretrizes da Paraíba de anos anteriores e, também, diretrizes de outros estados. Após, realizar a leitura e estudo do material encontrado, foi iniciada a construção do texto base dos Referenciais Curriculares do Ensino Fundamental, no nosso caso, da Educação Física (RCEF-EF) e o planejamento da primeira oficina com a participação dos professores da rede estadual.

Na I Oficina Pedagógica foram trabalhadas questões problematizadoras (feitas através de exposições/apresentações de slides), exposição de vídeos e leitura de textos, a fim de que os professores pudessem refletir sobre sua prática pedagógica. As questões foram formuladas com a intenção de entender como os professores desenvolvem suas aulas, que abordagem pedagógica utilizam, como percebem a Educação Física enquanto componente do currículo escolar, entre outras questões; e as dificuldades que eles encontram no cotidiano escolar (sejam elas pedagógicas e/ou de infra-estrutura - espaço, material).

Esse momento também serviu de caminho para dialogar sobre as experiências dos professores, para assim, partir para a construção do RCEF-EF, considerando as vivências e experiências acumuladas dos professores.

A I oficina também debateu concepções de sociedade e de

7 Foram contratados para o processo de elaboração do referencial da disciplina Educação Física, os professores Msnda. Áurea Augusta Rodrigues da Mata (UFPB/PMJP); e Ms. Jeimison de Araújo Macieira (PMJP). 
homem, apontando que a sociedade capitalista é excludente e se baseia na acumulação individual. Foi utilizada uma videoconferên$\mathrm{cia}^{8} \mathrm{com}$ a professora Celi Taffarel (UFBA), onde se faz um resgate dos principais argumentos históricos sobre a inserção da Educação Física no contexto escolar. Também foram utilizados como referenciais teóricos os estudos de Marx \& Engels (2007), Marx (2007), Mészáros (2005, 2009) e Saviani (2000, 2005, 2008). Tais referenciais serviram para compreender como esta sociedade forma homens fragmentados e desumanos. Essas características apontaram à necessidade de construir uma sociedade que vá de encontro aos valores e normas apregoadas pela sociedade capitalista, na busca pela formação de sujeitos históricos, que intervenham politicamente na realidade em que estão inseridos, ou seja,

Entender a realidade de forma crítica agrega novos significados a vida social destes entes, substanciando suas práticas pedagógicas no sentido de desvelar a essência destes fatos e acontecimentos, atribuindo-lhes novas possibilidades de atuação política nos seus espaços de intervenção (MACIEIRA, 2010, p. 29).

Faz-se necessário compreender o movimento da educação no atual momento histórico, inserida em um contexto social moldado pelo capital, ou seja, "não é possível, portanto, compreender radicalmente a história da sociedade contemporânea e, conseqüentemente, a história da educação contemporânea sem se compreender o movimento do capital" (SAVIANI, 2005, p. 17).

Na sequência, foram debatidos os objetivos da Educação Física escolar e a compreensão de currículo ampliado, delineando a necessidade de compreender as relações da Educação Física com ela mesma e com o mundo. Outra importante ação realizada na I Oficina foi a assimilação dos conceitos básicos para a Educação Física, imprescindíveis para ampliar e elevar o padrão cultural do ser humano, das competências e capacidades necessárias ao processo ensinoaprendizagem e dos conteúdos afeitos a Educação Física.

O momento final da I oficina esteve marcado pela avaliação da experiência, onde os presentes

8 A videoconferência utilizada foi um espaço realizado pela Secretaria de Educação do Estado da Bahia em 14 de julho de 2010, com a professora Celi Taffarel, onde a mesma proferiu uma palestra sobre o tema da inserção da disciplina Educação Física no currículo escolar. 
expuseram impressões sobre suas participações e, também, da abordagem metodológica do espaço como um todo. A primeira oficina foi um espaço gerador, onde os professores da rede assumiram a função de interlocutores dos consultores, apresentando as dificuldades encontradas por eles no cotidiano escolar, ou seja, foi debatida a realidade concreta da Educação Física nas escolas públicas da rede estadual de ensino da Paraíba. Desta forma, os professores contribuíram diretamente para elaboração dos referenciais.

A II Oficina (realizada entre 06 e 10 de dezembro) iniciou-se com a apresentação realizada pela coordenação do projeto, que fez um resgate do realizado na I oficina, para aqueles professores que estiveram ausentes. A consultora de diversidade sociocultural (tema que atravessa todas as áreas) socializou com todo o coletivo (consultores e professores) como ficou o documento de diversidade sociocultural.

Para finalizar a segunda oficina, foi realizada uma socialização entre todas as áreas, onde foram colocados os principais pontos debatidos durante a semana, se realizou a avaliação e foram ouvidas sugestões para serem incorporadas aos Referenciais Curriculares. A segunda oficina serviu para sistematizar a versão final do documento.

\section{Fundamentos teóricos e me- todológicos do Referencial do Estado da Paraíba}

A partir da primeira reunião com a coordenação do projeto de reformulação curricular ficou definido que a estrutura básica dos textos seria a mesma para todas as disciplinas. O texto de Educação Física inicia com o resgate histórico da inserção da disciplina no contexto educacional brasileiro, onde são mencionadas suas bases históricas desde as influências sofridas pelos movimentos ginásticos e militares nas primeiras quatro décadas do século $X X$, até emergência das principais abordagens de ensino na década de 1980: a psicomotricidade (LE BOULCH, 1983), a desenvolvimentista (GO TANI, 1988), a construtivista (FREIRE, 1989), a critico-superadora (COLETIVO DE AUTORES, 1992) e a criticoemancipatória (KUNZ, 1991), assim como também os PCN's e o ordenamento legal que fundamenta a nossa profissão.

No final do tópico se reafirma o papel da escola enquanto "um instrumento de luta, no sentido de que permite compreender meIhor o mundo [...] com a finalidade de transformá-lo, segundo interesses e anseios da classe trabalhadora" 
(FREITAS, 2009, p. 34) e o relaciona com o cotidiano e as necessidades históricas das escolas da rede estadual de ensino do Estado da Paraíba. Em suma, a realidade dessas escolas é de enfrentamento de dificuldades relacionadas a infraestrutura, a falta de corpo docente, a desvio de função, ou seja, disciplinas ministradas por professores que não tem formação específica na área, assim como, professores sem formação alguma.

Nas oficinas pedagógicas realizadas com os professores da rede estadual foi identificado que a abordagem Crítico-superadora, que tem como objeto de estudo a Cultura Corporal é a que mais se aproxima da realidade concreta dos professores e das contradições que caracterizam a sociedade paraibana. Professores e consultores consideraram esta abordagem como aquela que dá conta de responder às necessidades do cotidiano escolar e de garantir aos alunos o acesso ao conhecimento produzido e acumulado historicamente pela humanidade.

A segunda parte do documento apresenta os objetivos, construídos a partir da abordagem Critico-superadora, e os fundamentos teóricos e metodológicos, que orientam a organização do trabalho pedagógico nas escolas. É fundamental que através da organização do trabalho pedagógico, professores e alunos se percebam enquanto coletivo, no sentido de desenvolver ações que ajudem a resolver as problemáticas do cotidiano da escola, das aulas de Educação Física e de sua comunidade. Podemos afirmar, segundo os interesses da classe trabalhadora, que a escola tem a função social de elevar a capacidade de reflexão teórica dos alunos, e nessa perspectiva, elevar o padrão cultural esportivo da sociedade, consequentemente, ampliar o pensamento teórico dos alunos sobre a cultura corporal.

Na sequência o documento aponta a discussão da diversidade e Educação Física, onde se situou os temas socioculturais e sua relevância para conjunto das disciplinas. A temática da diversidade sociocultural presente no documento partiu das reflexões realizadas de forma coletiva nas oficinas pedagógicas e, principalmente, das problemáticas do cotidiano dos professores da rede estadual. No que se refere aos procedimentos didático-metodológicos, tomou-se como base uma perspectiva critica de educação, o método didático da prática social (SAVIANI, 2008), o qual prevê cinco etapas: a prática social, a problematização, a instrumentalização, a catarse e a nova prática social.

O texto finaliza trazendo uma critica ao modelo atual de avaliação, baseado na meritocracia 
e na aplicação de testes, com fins a seleção e classificação de alunos, indicando uma avaliação que aponte a aproximação ou o afastamento dos objetivos propostos, para que o professor possa tomar decisões e reorganizar o ensino. É preciso romper com o processo avaliativo somente por participação, frequência e rendimento atlético/físico; compreende-se a necessidade de avaliar levando em consideração os objetivos e critérios propostos para que, assim, a apropriação do conhecimento seja oportunizada de maneira significativa.

Entendendo que a função social do currículo "é ordenar a reflexão pedagógica do aluno de forma a pensar a realidade social desenvolvendo determinada lógica" (COLETIVO DE AUTORES, 1992, p. 27), é possível afirmar que para dar conta das proposições apresentadas nos referenciais curriculares referidos, faz-se necessário adotar uma perspectiva de currículo que possa responder as problemáticas significativas do cotidiano escolar, e que permita desvelar e superar as contradições que caracterizam as sociedades que, como a brasileira, estão divididas em classes; perspectiva essa materializada na proposta de currículo ampliado defendida pelo Coletivo de Autores (1992), que se caracteriza por ter "como eixo a constatação, a interpretação, a compreensão e a explicação da realidade social complexa e contraditória" (p.28), e, além disso, estabelece uma reflexão crítica a essa realidade.

\section{Considerações Finais}

Observando a necessidade de compreender a realidade das escolas públicas dos estados analisados, podemos perceber que, em linhas gerais, encontramos um cenário bastante conturbado, onde os professores de Educação Física sofrem com uma intensa precarização das condições de trabalho, tanto do ponto de vista teórico quanto das condições estruturais. Nesse sentido, as propostas de renovação dos referenciais curriculares em questão, estabelecem compromisso com uma educação problematizadora que está fundamentada nos alunos como sujeitos históricos, autênticos e incompletos - em permanente devir - e que fazem parte de uma realidade também incompleta e em contínua construção, pois a educação se constitui como uma prática social. Encaminhamento comum a todas as realidades analisadas, a formação continuada torna-se elemento imprescindível para a assimilação desses documentos. Outro importante elemento é o reconhecimento do avanço teórico-prático oportunizado pela vigência de todos esses 
referenciais, pois acreditamos que a adoção de perspectivas críticas contra-hegemônicas de educação e Educação Física, pode alterar significativamente a realidade dos sujeitos submetidos a essas pedagogias e contribuir para a construção de uma sociedade mais justa e solidária.

Portanto, após nos determos nas análises destes referenciais, podemos perceber consideráveis avanços teóricos na fundamentação destes documentos, sobretudo, porque constituem instrumentos de luta e de valorização da educação e, especificamente, do professor, enquanto facilitador na assimilação do conhecimento.

Esses conhecimentos que constituem os novos referenciais, elaborados na perspectiva da cultura corporal, propiciarão o desenvolvimento do pensamento crítico, historicamente sonegado aos filhos da classe trabalhadora. A apropriação do saber "burguês" para dotá-lo de novos significados permitirá à classe trabalhadora desarticular os interesses burgueses, colocandoos a serviço de sua classe e assim propiciar o desenvolvimento do homem omnilateral. Inserindo-o, na perspectiva da cultura históricoproletária, no dizer de Saviani. Isto é fundamental para poder identificar as contradições do atual modelo de educação e produção que é o responsável das desigualdades sociais que caracterizam as sociedades divididas em classes.

\section{Referenciais}

BRASIL. Lei $n^{\circ} 10.328$, de 12 de dezembro de 2001. Introduz a palavra obrigatório após a expressão curricular, constante do parágrafo $3^{\circ}$ artigo 26 da Lei 9.394, de 20 de dezembro de 1996, que estabelece as diretrizes e bases da educação nacional. Diário Oficial da República Federativa do Brasil. Poder Executivo. Brasília, DF, 23 dez.2001. Seção1, p. 1.

COLETIVO DE AUTORES. Metodologia do ensino de Educação Física. Coleção Magistério $2^{\circ}$ grau. Série formação do professor. São Paulo: Cortez, 1992.

FREITAS. Luiz Carlos de. A luta por uma pedagogia do meio: Revisitando o conceito. In: PISTRAK. M. M.(org) A Escola Comuna. São Paulo: Expressão Popular, 2009, p. 9-103.

HOFFMANN, Jussara. Avaliação mediadora: uma prática em construção da pré-escola à universidade. 14.ed. Porto Alegre: Educação e Realidade, 1998.

LEPEL/FACED/UFBA. Educação

Física: Referências Curriculares para a rede pública do estado da 
Bahia. Texto Didático destinado ao Seminário da DIREC $1 \mathrm{~A}$ e B. 2010

MACIEIRA, Jeimison de Araújo. Uma análise sobre as condições de realização do trabalho pedagógico dos professores de Educação Física na rede municipal de ensino da cidade de João Pessoa-PB. Dissertação de mestrado (Mestrado em Serviço Social) - Universidade Federal da Paraíba, 2010.

MARX, Karl. ENGELS, Friedrich.

Manifesto do partido comunista. São Paulo, Boitempo, 2007.

. A ideologia alemã. São Paulo,

Boitempo, 2007.

MÉSZÁROS, István. A educação

para além do capital. São Paulo, Boitempo, 2005.
PARANÁ. Secretaria de Educação. Diretrizes Curriculares da Educação Básica - Educação Física. Curitiba: SE-PR, 2008.

PERNAMBUCO. Secretaria de Educ ação. Orientações Teórico-Metodológicas: Ensino Fundamental - Educação Física. Recife: SE-PE, 2008.

SAVIANI, Demerval. Pedagogia histórico-crítica: primeiras aproximações. $10^{\circ} \mathrm{ed}$. Campinas - SP, Autores Associados, 2008.

SAVIANI, Demerval et al. As transformações do capitalismo, do mundo do trabalho e educação. In: LOMBARDI, J.C., SAVIANI, D. e SANFELICE, J.L. (orgs.). Capitalismo, trabalho e educação. São Paulo, Ed. Autores Associados, $3^{\circ} \mathrm{Ed} .2005$.

\section{ABSTRATC}

The article tries to do an overview of the discussions that are happening nationally in the recasting of the Core Curriculum Benchmarks for Physical Education, placing it in the states of Parana, Pernambuco, Bahia and, in particular, in Paraíba. Notes on the discussions held in the states cited a tendency to build their curriculum frameworks having as object the Body Culture. This proposal is the development perspective omnilateral and affirms the historical and dialectical materialism as a theory of knowledge. Recognizes the school as an instrument of struggle, to give evidence to a better understanding of reality.

Keywords: Body Culture; School Physical Education, Curriculum Benchmarks Basic Physical Education 